\title{
A large fibroma polyp of labia majora
}

\section{Aman Deep Raj ${ }^{1 *}$, Murali Mohan Soma ${ }^{2}$, S. P. Khajuria ${ }^{3}$}

\author{
${ }^{1}$ Department of Obstetrics and Gynecology, ${ }^{2}$ Department of Surgery, ${ }^{3}$ Department of Pathology, MH Gwalior, Morar \\ Cantt, Gwalior, Madhya Pradesh, India
}

Received: 02 October 2018

Accepted: 01 November 2018

\section{*Correspondence:}

Dr. Aman Deep Raj,

E-mail: amandeepraj@yahoo.co.uk

Copyright: (C) the author(s), publisher and licensee Medip Academy. This is an open-access article distributed under the terms of the Creative Commons Attribution Non-Commercial License, which permits unrestricted non-commercial use, distribution, and reproduction in any medium, provided the original work is properly cited.

\begin{abstract}
Fibroepithelial stromal polyps are benign proliferations which are usually polypoid or pedunculated, and less than $5 \mathrm{~cm}$ in size. They are generally single lesions but can be multiple during pregnancy. They can be polypoid or pedunculated and are usually solitary. Symptoms usually include bleeding, discharge and general discomfort with sensation of a mass. They typically have a central fibrovascular core and contain stellate and multinucleated stromal cells which are best seen beneath the surface epithelium. True myxoid stroma is absent. Although vulvovaginal fibroepithelial stromal polyps are well documented, a giant variant such as the one authors report here is rather rare. To the knowledge, present case is the largest fibroepithelial stromal polyp compared to others reported in the literature.
\end{abstract}

Keywords: Fibroma polyp, Giants, Labial, Labia majora, Skin tag

\section{INTRODUCTION}

The fibroepithelial polyps (FEPs), which are also referred to as acrochordons or skin tags, are common lesions that typically occur in adults, especially obese women. They show a predilection for the neck, axillae, and groin. FEPs of the lower genital tract often develop in young to middle-aged women and present more commonly in the vagina. They are less common in the vulva and are rarely present in the cervix. ${ }^{1}$ These lesions typically do not grow larger than $5-\mathrm{cm}$ in diameter and are found incidentally during routine gynaecologic exams. ${ }^{2}$ They can be polypoid or pedunculated and are usually solitary. Symptoms usually include bleeding, discharge and general discomfort with sensation of a mass. Biopsy is often necessary to make a definitive diagnosis as their clinical features may overlap with those of malignant neoplasms and immunohistochemistry is of limited help. ${ }^{3,4}$ Although the stromal polyp is benign, its differential diagnosis includes some malignant vulva lesions making it critical to ensure that an accurate pathologic diagnosis is made.

These vulvovaginal tumours include fibroepithelial stromal polyps, aggressive (deep) angiomyxoma, superficial angiomyxoma, angiomyo fibro blastoma, cellular angiofibroma and (prepubertal) valval fibroma. Diagnosis often relies on the identification of subtle morphological differences between these different tumours and clinical correlation is paramount. In the diagnosis of gynecological neoplasms, CT and magnetic resonance imaging might be preferred, especially in patients with a history of carcinoma.

However, ultrasound examination may be a more suitable first-line diagnostic approach in terms of costeffectiveness, wide availability, speed and the capacity for dynamic exploration. It can help in the differential diagnosis of lesions of the inguinal area and vulva such as hernia, lymphadenopathy and neck canal cyst. 


\section{CASE REPORT}

A 55-year-old female $\mathrm{P}_{3} \mathrm{~L}_{3}$ all vaginal deliveries presented with a five-year history of a labial mass that was initially slow-growing pedunculated mass which caused difficulty in walking and discomfort. The mass was not associated with pain, fever or trauma.

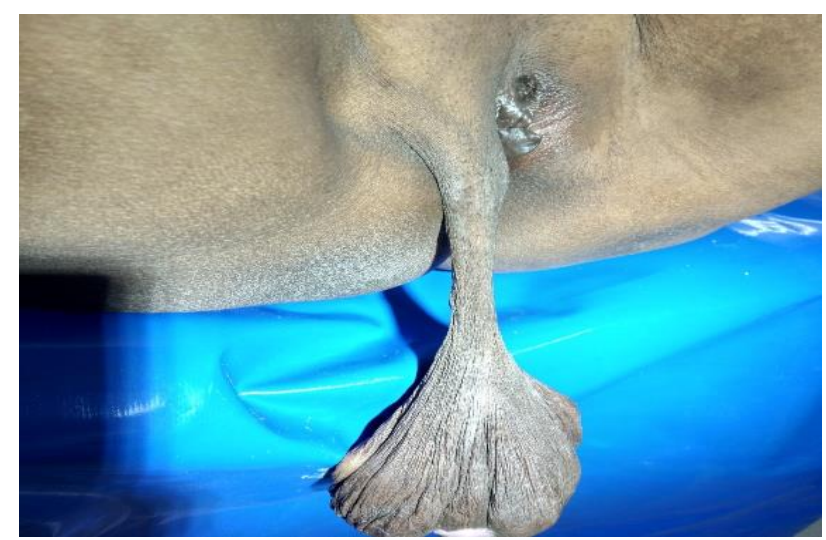

Figure 1: Fibroma polyp hanging from right labia majora.

On examination, there was a large $22 \times 9 \mathrm{~cm}$ pedunculated mass arising from right labia majora which showed signs of decubitus ulceration at the distal dependent end. Translucency test was negative, and auscultation failed to reveal any bruit or gurgling sound.

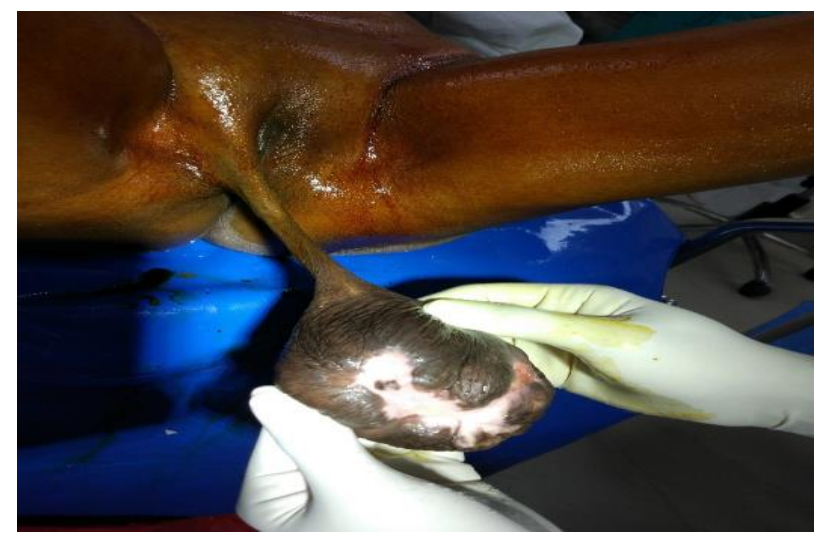

Figure 2: Fibrosis and ulceration on the most dependent part of the polyp.

Bedside ultrasound showed a homogenous mass with fluid pockets, but no bowel segments were found within. However, color doppler showed evidence of vascularity. Her past medical and surgical history was not significant and HIV, HBsAg and VDRL screen was negative. Her family history was not significant. Her vitals were stable on presentation and she was afebrile with no evidence of any lymphadenopathy. Breast examination did not reveal any abnormality. Pelvic examination showed healthy cervix with no vaginal discharge. No cyst was found in the lateral vaginal wall. Uterus was normal size with small bilateral ovaries. There was no history of irradiation, trauma, or topical treatment. The results of routine laboratory tests were normal. Due to the presence of a pedicle, a congenital lesion was in the clinical differential. However, the large size and the extent of the lesion raised the possibility of an aggressive or even malignant lesion.

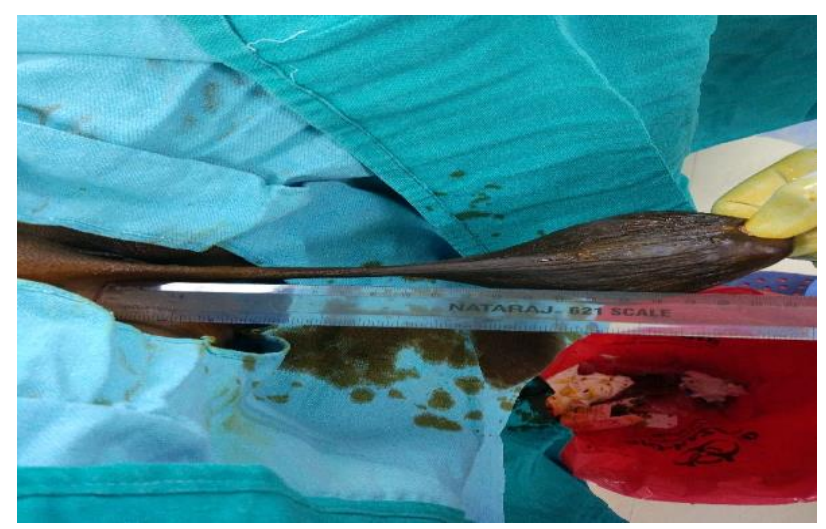

Figure 3: Preoperative $22 \mathrm{~cm}$ polyp.

The patient subsequently underwent local excision of the lesion via diathermy at the base of the stalk (Figure 3 and $4)$.

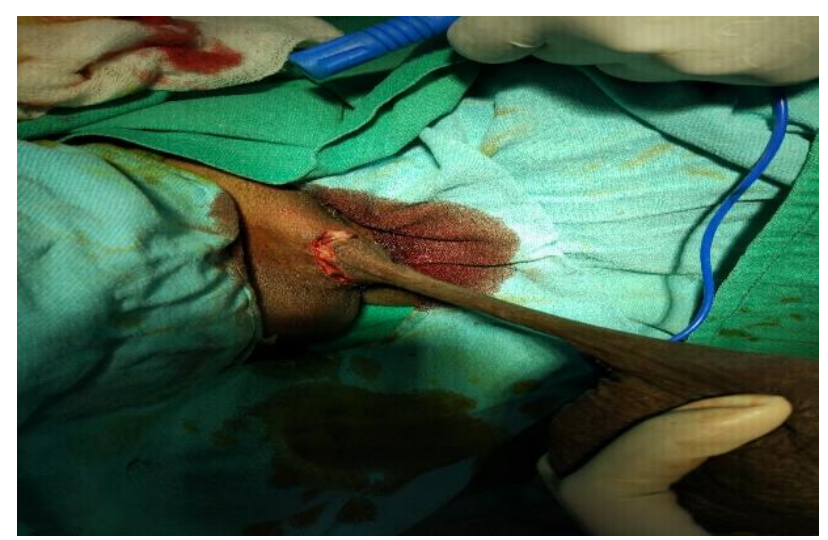

Figure 4: Intraop-excision from the base.

The lesion was surgically removed without difficulty. The lower genital tract was otherwise normal.

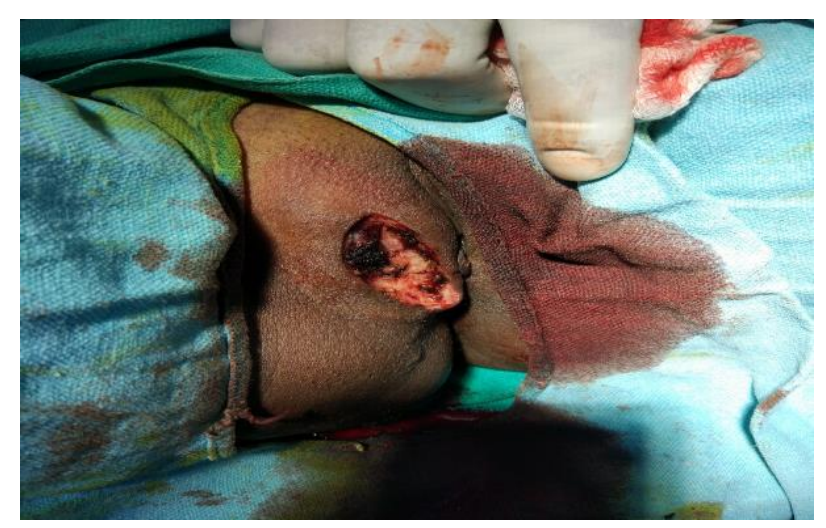

Figure 5: Intraop-after excision of polyp. 


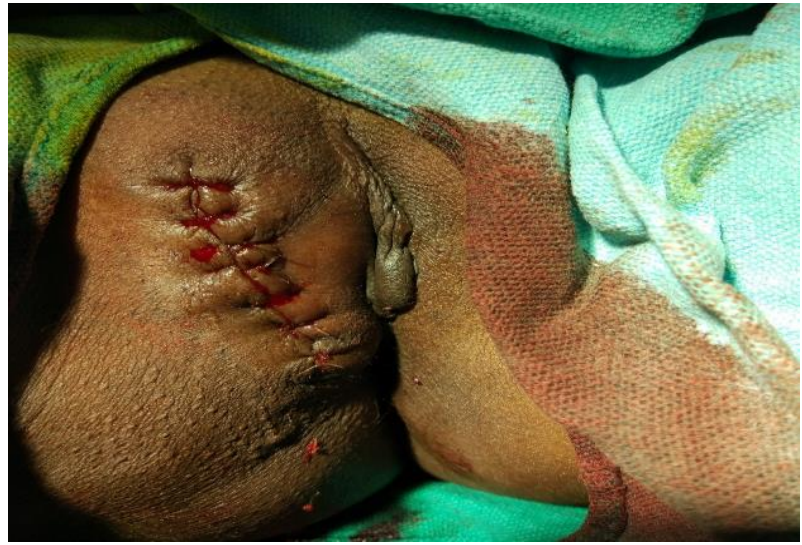

Figure 6: Wound closure post excision.

The patient was well and discharged during her follow-up visit three weeks post-operatively.

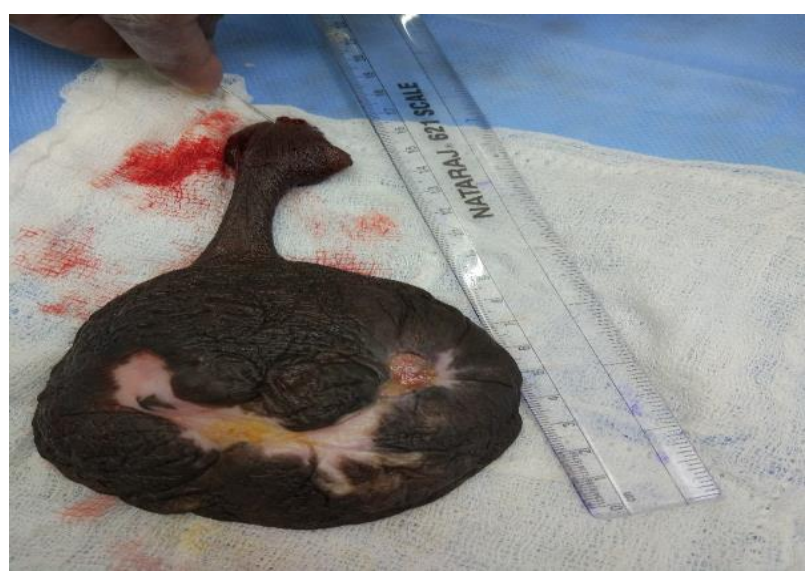

Figure 7: Gross examination of excised polyp showing fibrosis and ulcerated dependent part.

The excised mass weighed about 500gms with fibrosis and ulcerated dependent end.

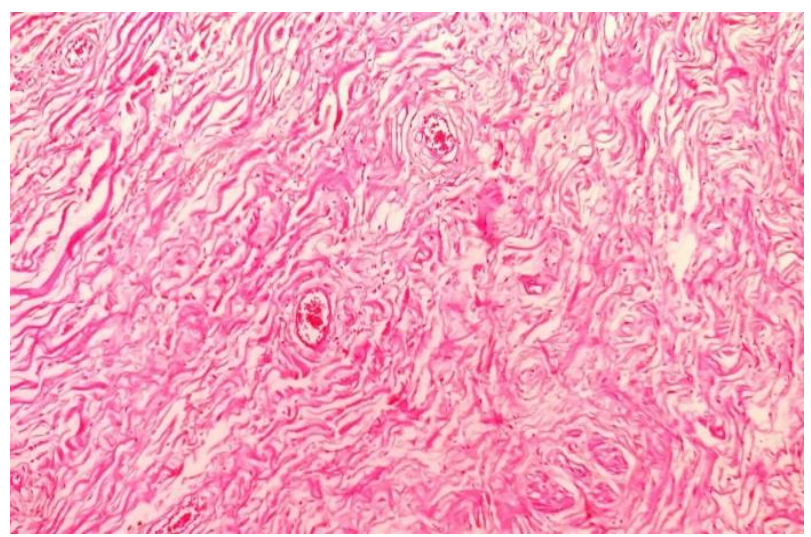

Figure 8: Stroma is edematous, hypocellular and myxoid (10X).

Excision biopsy revealed solid fibrous tissue with vascular pedicle on gross examination.

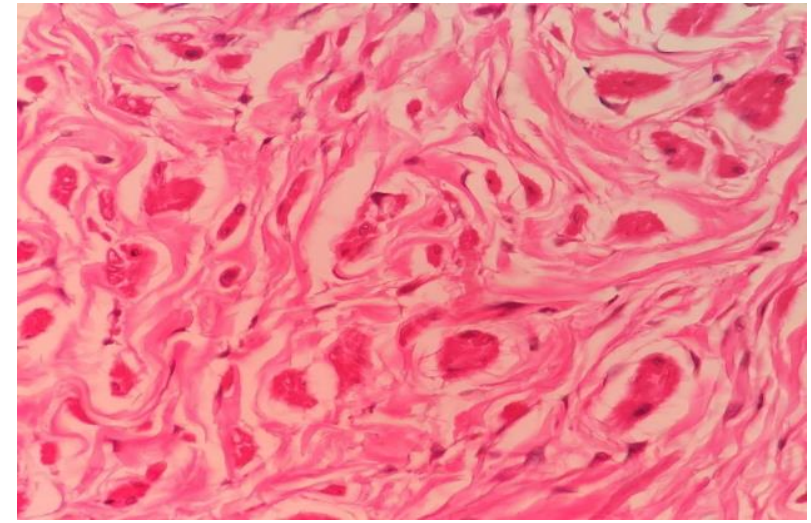

Figure 9: Stroma showing stellate and multinucleated cells $(40 \mathrm{X})$.

Histopathological examination showed fibrous tissue without atypia.

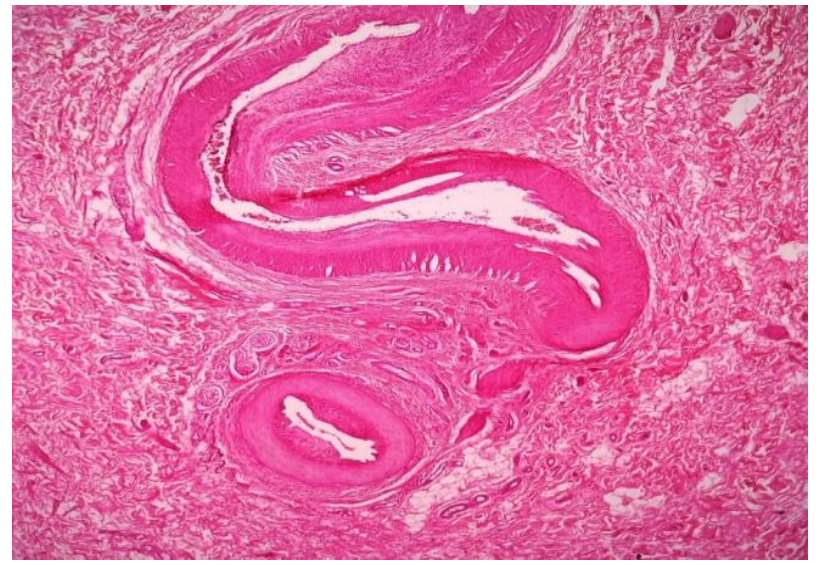

Figure 10: Thickened blood vessels from central fibrovascular core of stalk (10X).

\section{DISCUSSION}

Fibroepithelial stromal polyps are benign proliferations which are usually polypoid or pedunculated, and less than $5 \mathrm{~cm}$ in size. ${ }^{5}$ Vulval fibroma is a rare benign tumour that is predominantly found in women of reproductive age group; though they have been reported in infants, post-menopausal and pregnant women. ${ }^{6}$ The tumour may arise from either the deep connective tissue of introitus, labia majora, perineal body or round ligament. ${ }^{7,8}$ They are generally single lesions but can be multiple during pregnancy. They typically have a central fibrovascular core and contain stellate and multinucleated stromal cells which are best seen beneath the surface epithelium. True myxoid stroma is absent. Although vulvovaginal fibroepithelial stromal polyps are well documented, a giant variant such as the one authors report here is rather rare. To the knowledge, present case is the largest fibroepithelial stromal polyp compared to others reported in the literature. Although different psychosocial problems have been reported, but patients in India, try to conceal it. This patient reported to us only because of 
bleeding from the ulcer and difficulty in walking due to the huge size of the tumour. Other reports which had relatively large fibroepithelial stromal polyps include one case of a $10 \mathrm{~cm}$ lesion in a young girl with a history of congenital lymphoedema, and one case of a $15 \mathrm{~cm}$ lesion occurring in association with valval psoriasis., ${ }^{9,10}$ Another case report documented a $15 \mathrm{~cm}$ giant fibroepithelial stromal polyp and described the sonographic features as an adjunct to the diagnosis of fibroepithelial stromal polyp in large vulvovaginal lesions. ${ }^{11}$ Other vulvovaginal lesions that can mimic fibroepithelial stromal polyps because of their well-circumscribed margins are angiomyofibroblastomas, superficial angiomyxomas and cellular angiofibromas. Angiomyofibroblastomas are benign tumour which can be distinguished from fibroepithelial stromal polyps histologically because they tend to have alternating cellularity with clusters of epithelioid stromal cells surrounding small capillaries. They are cured by local excision. Vulvovaginal superficial angiomyxomas are also different histologically because they have a multinodular pattern of growth and abundant true myxoid stroma. Although benign, they have a recurrence rate exceeding $30 \%$ therefore requiring clear margins. ${ }^{5}$

Cellular angiofibromas are more cellular spindle cell lesions with hyalinized blood vessels. They are benign and are managed by complete local excision. Another consideration in vulvovaginal lesions presenting in young girls is the more recently described prepubertal valval fibromas. However, these usually have ill-defined margins involving submucosa or subcutis. ${ }^{12}$ In addition, the spindle cells in these tumour are typically positive for CD34. ${ }^{13}$

Funding: No funding sources Conflict of interest: None declared

Ethical approval: Not required

\section{REFERENCES}

1. Carter J, Elliott P, Russell P. Bilateral fibroepithelial polypi of labium minus with atypical stromal cells. Pathol.1992:24(1);37-9.

2. Nucci MR, Oliva E. Gynecologic Pathology E-Book: A Volume in the Series: Foundations in Diagnostic Pathology. Elsevier Health Sciences; 2009.
3. Nucci MR, Young RH, Fletcher CD. Cellular pseudosarcomatous fibroepithelial stromal polyps of the lower female genital tract: an underrecognized lesion often misdiagnosed as sarcoma. Am J Surgical Pathol. 2000;24(2):231-40.

4. Ostör AG, Fortune DW, Riley CB. Fibroepithelial polyps with atypical stromal cells (pseudosarcoma botryoides) of vulva and vagina. A report of 13 cases. Int J Gynecol Pathol: Official J Int Society Gynecol Pathol. 1988;7(4):351-60.

5. Kurman RJ, Ellenson LH, Ronnett BM. In: Blaustein's Pathology of the Female Genital Tract. $6^{\text {th }}$ ed. US: Springer; 2011.

6. Wilkinson EJ, Xie D. Benign diseases of the vulva. In: Kurman RJ, ed. Blausteinâ€ $€^{\mathrm{TM}_{\mathrm{S}}}$ pathology of the female genital tract. $5^{\text {th }}$ ed. New Delhi: SpringerVerlag; 2002:37-98.

7. De Lima A. Fibroma of the vulva (Molluscum Pendulum). Obstet Gynaecol Surv. 1952;7:845-6.

8. Berlin M, Berlin S. Fibroma of the vulva: a case report. J Reprod Med. 2007;52:533-4.

9. Orosz Z, Lehoczky O, Szoke J, Pulay T. Recurrent giant fibroepithelial stromal polyp of the vulva associated with congenital lymphedema. Gynecol Oncol. 2005;98(1):168-71.

10. Dane C, Dane B, Cetin A, Erginbas M, Tatar Z. Association of psoriasis and vulval fibroepithelial polyp: first reported case. Am J Clin Dermatol. 2008;9(5):333-5.

11. Bozgeyik Z, Kocakoc E, Koc M, Ferda Dagli A. Giant fibroepithelial stromal polyp of the vulva: extended field-of-view ultrasound and computed tomographic findings. Ultrasound Obstet Gynecol. 2007;30(5):791-2.

12. Iwasa Y, Fletcher CD. Distinctive prepubertal vulval fibroma: a hitherto unrecognized mesenchymal tumor of prepubertal girls: analysis of 11 cases. Am J Surg Pathol. 2004;28(12):1601-8.

13. Nucci MR. Mesenchymal lesions of the lower genital tract. Surg Pathol Clin. 2009;2(4):603-23.

Cite this article as: Raj AD, Soma MM, Khajuria SP. A large fibroma polyp of labia majora. Int J Reprod Contracept Obstet Gynecol 2019;8:762-5. 